\title{
Lewy body dementia: Ursodeoxycholic acid as a putative treatment for gastrointestinal dysfunction
}

\author{
Mohsen Khosravi
}

(1) Department of Psychiatry and Clinical Psychology, Zahedan University of Medical Sciences, Zahedan, Iran.

This article is distributed under the terms of the Creative Commons Attribution Noncommercial License (CC BY-NC 4.0) which permits any noncommercial use, distribution, and reproduction in any medium, provided the original author(s) and source are credited.

\begin{abstract}
The autonomic nervous system (ANS) is a part of the peripheral nervous system that regulates internal organs function at an involuntary unconscious level. Recent evidence has shown that autonomic dysfunction is a common feature of Lewy body dementia (LBD). A wide range of autonomic symptoms may occur in LBD, which are correlated with poor prognosis. However, there is still no evidence-based approach to developing the best therapeutic strategy for autonomic dysfunction (particularly gastrointestinal symptoms) among LBD patients. This paper was intended to present a new perspective on ursodeoxycholic acid and its potential effects for treating gastrointestinal dysfunction in LBD patients.
\end{abstract}

Key Words: Gastrointestinal dysfunction; Lewy body dementia; ursodeoxycholic acid.

Eur J Transl Myol 2021; 31 (2): 9876. doi: 10.4081/ejtm.2021.9876

Lewy body dementia (LBD) is the second most common type of neurodegenerative dementia, associated with alpha-synuclein deposition in brain neurons. ${ }^{1}$ These abnormal deposits, called Lewy bodies, can cause changes in cognition, behavior, and movement by affecting brain chemicals. Besides, recent evidence has demonstrated that the presence of neuropathological lesions in the autonomic nervous system (ANS) can account for the belief that ANS may be influenced by LBD. ${ }^{2}$ A wide range of autonomic symptoms may occur in LBD, which are related to faster disease progression and shorter survival time. Among them, the gastrointestinal tract as one of the internal organs under the control of the ANS is probably affected in LBD with symptoms ranging between dysphagia, gastroparesis, and constipation. ${ }^{1,2}$

Dysphagia, possibly resulting from involvement of the dorsal motor nucleus of the vagus nerve, can be associated with varying degrees of swallowing dysfunction, as well as increased risk of developing aspiration pneumonia and mortality among LBD patients. ${ }^{2}$ Regarding potential therapeutic implications of bile acids, animal models in biological and biomedical research demonstrated that esophageal exposure to ursodeoxycholic acid (UDCA) can decrease esophageal contraction amplitudes. $^{3}$ In this respect, a recent randomized control trial has shown a significant reduction in dysphagia following at least three months of treatment with UDCA. ${ }^{4}$ These findings have revealed that UDCA may be an alternative pharmacological agent in reducing dysphagia among LBD patients without clinically significant side effects.

Furthermore, Gastroparesis appears to be affected by the severity of motor impairment in LBD. ${ }^{1}$ In addition to causing symptoms such as fullness, reflux, and excess belching, impaired gastric motility can also influence the absorption rate of drugs. ${ }^{1}$ A recent experimental study on fasted rats illustrated that UDCA perfusion into stomach can lead to shorter cycle duration of gastroduodenal migrating myoelectric complex (MMC), longer duration of duodenal phase III, and shorter cycle duration of antral phase III. ${ }^{5}$ Accordingly, previous studies have suggested that UDCA drain into the duodenum affects the duodenal MMC and stimulates the release of endogenous motilin from the mucous of duodenum. ${ }^{5,6}$ Motilin, in turn, may influence the timing of antral MMC activity. ${ }^{7}$ These findings show that Comprehensive therapy using UDCA, possibly by releasing endogenous motilin, might cause and strengthen the gastric response to initiation of the antral MMC, which can lead to significant improvement in heartburn frequency and other extraesophageal manifestations of gastroesophageal reflux disease (GERD). ${ }^{4,5}$ Besides, the use of UDCA seems to contribute to a decrease in body weight (up to $5 \mathrm{~kg} / \mathrm{month}$ mainly in obesity class I and II) and GERD by improving oroileal transit time and reducing bile cholesterol saturation. ${ }^{4,8,9}$ 


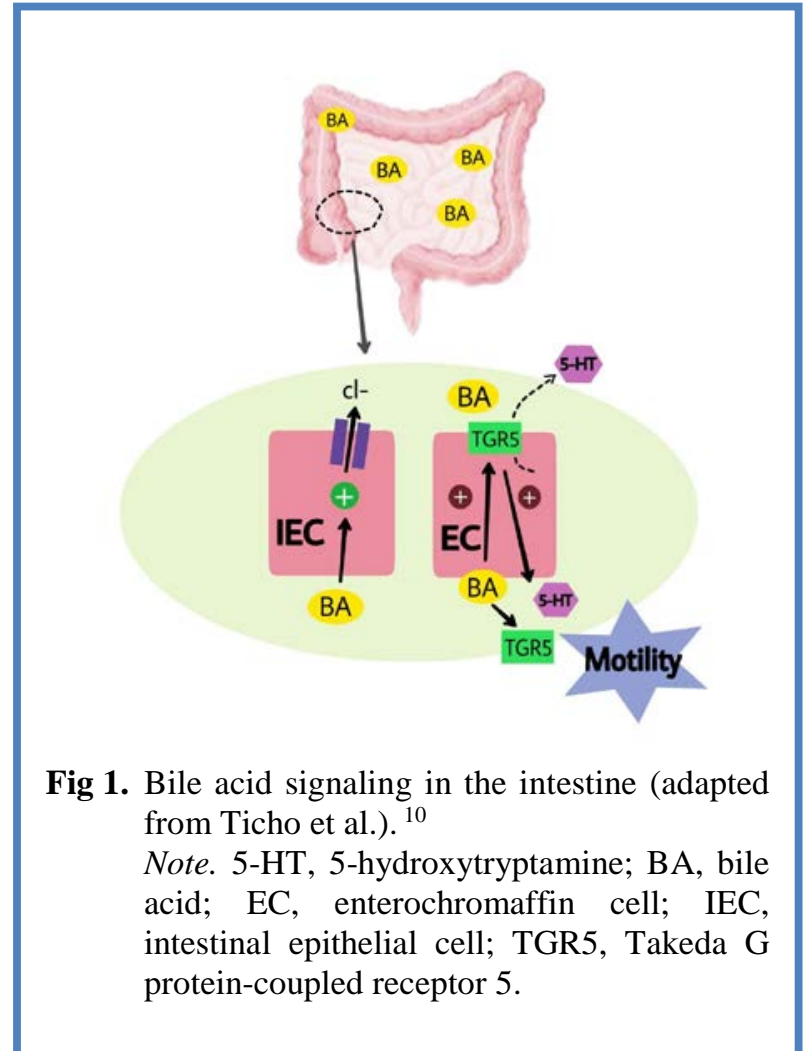

Another common gastrointestinal symptom in LBD is constipation, whose most important cause is prolonged colon transit time. Constipation can also be aggravated for reasons such as sedentary lifestyle, poor fiber and fluid intake, and taking opiates or anticholinergics. ${ }^{1}$ Recent evidence has revealed that overproduction of bile acids may promote diarrhea by the two following mechanisms: (i) inducing chloride secretion in the intestinal epithelial cell through the unknown receptor(s); (ii) activating Takeda $G$ protein-coupled receptor 5 on enterochromaffin cells and promoting 5hydroxytryptamine release and motility. ${ }^{10}$ These findings suggest the possible role of UDCA in the induction of colonic motility in LBD patients (see Figure 1).

All in all, given the heterogeneous nature of LBD and the wide range of subjective complaints in multiple organ systems, the underlying molecular mechanisms of the disease and its novel therapeutic targets need to be more accurately explored. According to this perspective, UDCA may be considered a potential agent for treating gastrointestinal dysfunction among LBD patients. However, further investigations in this field need to be carried out through experimental randomized controlled trials.

\section{List of acronyms}

ANS - Autonomic nervous system

GERD - Gastroesophageal reflux disease

LBD - Lewy body dementia

MMC - Migrating myoelectric complex

UDCA - Ursodeoxycholic acid

\section{Author contributions}

Mohsen Khosravi fully wrote the article.

\section{Acknowledgments}

\section{Funding None}

\section{Conflict of Interest}

The author declares no financial, personal, or other conflicts of interest.

\section{Ethical Publication Statement}

I confirms that I have read the Journal's position on issues involved in ethical publication and affirms that this report is consistent with those guidelines.

\section{Corresponding Author}

Mohsen Khosravi, MD, Department of Psychiatry and Clinical Psychology, Baharan Psychiatric Hospital, Zahedan University of Medical Sciences, Postal Code: 9813913777, Zahedan, Iran.

Tel: +98-5433522636, Fax: +98-5433518352.

ORCID ID: 0000-0003-2970-6309

Email: dr_khosravi2016@yahoo.com

\section{References}

1. Taylor JP, McKeith IG, Burn DJ, Boeve BF, Weintraub D, Bamford C, Allan LM, Thomas AJ, O'Brien JT. New evidence on the management of Lewy body dementia. Lancet Neurol. 2020 Feb;19(2):157-169. doi: 10.1016/S14744422(19)30153-X. Epub 2019 Sep 10.

2. Allan LM. Diagnosis and Management of Autonomic Dysfunction in Dementia Syndromes. Curr Treat Options Neurol. 2019 Jul 10;21(8):38. doi: 10.1007/s11940-019-0581-2.

3. Rocha MS, Herbella FA, Del Grande JC, Ferreira AT, Tahan C, Patti MG. Effects of ursodeoxycholic acid in esophageal motility and the role of the mucosa. An experimental study. Dis Esophagus. 2011 May;24(4):291-4. doi: 10.1111/j.14422050.2010.01137.x.

4. Sirchak YS. Clinical efficacy of ursodeoxycholic acid in the comprehensive treatment of patients with obesity and gastroesophageal reflux disease. Gastroenterologia. 2018;52(4):207-15. doi: 10.22141/2308-2097.52.4.2018.154140.

5. Fang P, Dong L, Luo JY, Wan XL, Du KX, Chai NL. Effects of motilin and ursodeoxycholic acid on gastrointestinal myoelectric activity of different origins in fasted rats. World J Gastroenterol. 2004 Sep 1;10(17):2509-13. doi: 10.3748/wjg.v10.i 17.2509.

6. Portincasa P, Peeters TL, van Berge-Henegouwen GP, van Solinge WW, Palasciano G, van Erpecum KJ. Acute intraduodenal bile salt depletion leads to strong gallbladder contraction, altered antroduodenal motility and high plasma motilin levels in humans. Neurogastroenterol Motil. 2000 
Oct;12(5):421-30. doi: 10.1046/j.13652982.2000.00217.x.

7. Luiking YC, Peeters TL, Stolk MF, Nieuwenhuijs VB, Portincasa P, Depoortere I, van Berge Henegouwen GP, Akkermans LM. Motilin induces gall bladder emptying and antral contractions in the fasted state in humans. Gut. 1998 Jun;42(6):830-5. doi: 10.1136/gut.42.6.830.

8. Colecchia A, Mazzella G, Sandri L, Azzaroli F, Magliuolo M, Simoni P, Bacchi-Reggiani ML, Roda E, Festi D. Ursodeoxycholic acid improves gastrointestinal motility defects in gallstone patients. World J Gastroenterol. 2006 Sep 7;12(33):5336-43. doi: 10.3748/wjg.v12.i33.5336.
9. Nirwan JS, Hasan SS, Babar ZU, Conway BR, Ghori MU. Global Prevalence and Risk Factors of Gastro-oesophageal Reflux Disease (GORD): Systematic Review with Meta-analysis. Sci Rep. 2020 Apr 2;10(1):5814. doi: 10.1038/s41598-02062795-1.

10. Ticho AL, Malhotra P, Dudeja PK, Gill RK, Alrefai WA. Bile Acid Receptors and Gastrointestinal Functions. Liver Res. 2019 Mar;3(1):31-39. doi: 10.1016/j.livres.2019.01.001. Epub 2019 Jan 14.

Submission: May 25, 2021 Accepted for publication: June 2, 2021 